OPEN ACCESS

Edited by:

Jing-Ren Zhang

Tsinghua University, China

Reviewed by:

Roger Derek Pechous,

University of Arkansas for Medical Sciences, USA

Girija Ramakrishnan,

University of Virginia, USA

*Correspondence:

Anders Sjösted

anders.sjostedt@umu.se

${ }^{\dagger}$ These authors have contributed equally to this work.

Received: 19 October 2016 Accepted: 10 January 2017 Published: 24 January 2017

Citation:

Honn M, Lindgren H, Bharath GK and Sjöstedt $A$ (2017) Lack of OxyR and KatG Results in Extreme Susceptibility of Francisella tularensis LVS to Oxidative Stress and Marked Attenuation In vivo.

Front. Cell. Infect. Microbiol. 7:14. doi: 10.3389/fcimb.2017.00014

\section{Lack of OxyR and KatG Results in Extreme Susceptibility of Francisella tularensis LVS to Oxidative Stress and Marked Attenuation In vivo}

\author{
Marie Honn ${ }^{\dagger}$, Helena Lindgren ${ }^{\dagger}$, Gurram K. Bharath and Anders Sjöstedt * \\ Clinical Bacteriology, and Laboratory for Molecular Infection Medicine Sweden, Department of Clinical Microbiology, Umeå \\ University, Umeå, Sweden
}

Francisella tularensis is an intracellular bacterium and as such is expected to encounter a continuous attack by reactive oxygen species (ROS) in its intracellular habitat and efficiently coping with oxidative stress is therefore essential for its survival. The oxidative stress response system of $F$. tularensis is complex and includes multiple antioxidant enzymes and pathways, including the transcriptional regulator OxyR and the $\mathrm{H}_{2} \mathrm{O}_{2}$-decomposing enzyme catalase, encoded by katG. The latter is regulated by OxyR. A deletion of either of these genes, however, does not severely compromise the virulence of $F$. tularensis and we hypothesized that if the bacterium would be deficient of both catalase and OxyR, then the oxidative defense and virulence of $F$. tularensis would become severely hampered. To test this hypothesis, we generated a double deletion mutant, $\triangle O x y R / \Delta k a t G$, of $F$. tularensis LVS and compared its phenotype to the parental LVS strain and the corresponding single deletion mutants. In accordance with the hypothesis, $\triangle 0 x y R / \Delta k a t G$ was distinctly more susceptible than $\triangle 0 x y R$ and $\Delta k a t G$ to $\mathrm{H}_{2} \mathrm{O}_{2}, \mathrm{ONOO}^{-}$, and $\mathrm{O}_{2}^{-}$, moreover, it hardly grew in mouse-derived BMDM or in mice, whereas $\Delta k$ katG and $\triangle 0 x y R$ grew as well as F. tularensis LVS in BMDM and exhibited only slight attenuation in mice. Altogether, the results demonstrate the importance of catalase and OxyR for a robust oxidative stress defense system and that they act cooperatively. The lack of both functions render $F$. tularensis severely crippled to handle oxidative stress and also much attenuated for intracellular growth and virulence.

Keywords: Francisella tularensis, OxyR, KatG, oxidative stress, virulence

\section{INTRODUCTION}

Francisella tularensis, a Tier 1 select agent and the causative agent of tularemia, is a zoonotic, facultative intracellular bacterium with two clinically relevent subspecies, tularensis and holarctica, the former of which causes an aggressive disease with high mortality if left untreated (Oyston et al., 2004). Although there is no licensed vaccine against this potential bioterrorism agent, the subspecies holarctica live vaccine strain, LVS, is used to vaccinate laboratory workers, and is widely used in Francisella research as it is attenuated in humans, but retains its virulence in mice (Sjöstedt, 2006; Conlan, 2011). 
Francisella tularensis is capable of infecting numerous cell types, including professional phagocytes, like macrophages. Upon phagocytosis, it transiently resides within the phagosome before escaping into the cytosol to replicate (Bröms et al., 2010; Chong and Celli, 2010). Phagocytes constitute a hostile environment utilizing a wide array of anti-bacterial mechanisms, such as phagosome acidification, disruption of pathogen membrane integrity, removal or sequestration of nutrients, and the production of reactive oxygen species (ROS) (Flannagan et al., 2009) and since $F$. tularensis is an intracellular bacterium, it will encounter a continuous exposure to ROS. Vital macromolecules, such as proteins and DNA, will react with ROS, thereby disrupting their functions (Fridovich, 1998; Schaible and Kaufmann, 2004; Flannagan et al., 2009). There are several ROS with potent antibacterial effects, such as superoxide and $\mathrm{H}_{2} \mathrm{O}_{2}$. The former is produced at high levels by the phagocyte oxidase (phox) and it rapidly combines with nitric oxide (NO), which is produced at high levels by inducible nitric oxide synthase (iNOS), to form peroxynitrite, a highly reactive compound. $\mathrm{H}_{2} \mathrm{O}_{2}$ is toxic perse, but the damage it exerts can be exacerbated in combination with intracellular ferrous iron, resulting in the formation of hydroxyl radicals $\left(\mathrm{HO}^{\bullet}\right)$ and hydroxide anions $\left(\mathrm{OH}^{-}\right)$through the Fenton reaction.

Reactive oxygen species (ROS) are not only formed during host attack, but low levels are also formed as by-products of normal aerobic metabolism. Thus, pathogens, in particular intracellular pathogens, have a pressing need for defense mechanisms to combat the ever present levels of ROS, but even more so to combat the assault of ROS experienced within a host (Betteridge, 2000). The critical roles of ROS and NO for the host defense against tularemia are illustrated by the extreme susceptibility of phox-deficient and iNOS-deficient mice to an F. tularensis infection (Lindgren et al., 2004). Moreover, ex vivo, it has been demonstrated that the requirements for host protection vary depending on the cell type investigated, since killing of $F$. tularensis by mouse peritoneal cells is NO-dependent, but NOindependent by mouse pulmonary cells (Anthony et al., 1992; Polsinelli et al., 1994; Lindgren et al., 2005).

The oxidative stress defense system of Escherichia coli has been extensively studied and includes numerous detoxifying enzymes, such as catalase, superoxide dismutases (SODs), alkyl hydroperoxide reductase (Ahp), and the $\mathrm{H}_{2} \mathrm{O}_{2}$-activated transcriptional regulator OxyR. The latter combats the effect of $\mathrm{H}_{2} \mathrm{O}_{2}$ by dual mechanisms, since it regulates the expression of both catalase and the ferric uptake regulator (Fur) (Farr and Kogoma, 1991; Zheng et al., 1998, 1999; Pomposiello and Demple, 2001). Catalase renders $\mathrm{H}_{2} \mathrm{O}_{2}$ harmless by degrading it to oxygen and water, whilst Fur down-regulates the expression of genes involved in iron uptake, thus limiting the amount of iron with which $\mathrm{H}_{2} \mathrm{O}_{2}$ can combine in the Fenton reaction (Andrews et al., 2003; Troxell and Hassan, 2013). Catalase, SODs, AhpC and other detoxifying enzymes are employed as oxidative stress defense mechanisms also by F. tularensis (Bakshi et al., 2006; Lindgren et al., 2007; Melillo et al., 2009; Binesse et al., 2015). The F. tularensis catalase, encoded by kat $G$, mediates $\mathrm{H}_{2} \mathrm{O}_{2}$ tolerance and is known to be important for the virulence of $F$. tularensis LVS (Lindgren et al., 2007). SodB, FeSOD, and SodC, CuZnSOD, are both known to be important for the dismutation of $\mathrm{O}_{2}^{-}$ in F. tularensis, and SodB further acts in the defense against oxidative stress by harnessing iron (Bakshi et al., 2006; Melillo et al., 2009). The F. tularensis AhpC enzyme is important for the detoxification of $\mathrm{O}_{2}^{-}$and peroxynitrite $\left(\mathrm{ONOO}^{-}\right)$, but not of $\mathrm{H}_{2} \mathrm{O}_{2}$, in the highly virulent SCHU S4 strain (Binesse et al., 2015), but the importance in the LVS strain is yet unknown. F. tularensis also encodes an $\operatorname{oxyR}$ homolog, the role of which has been studied recently (Ma et al., 2016). It was found that the absence of OxyR rendered LVS defective for oxidative stress defense, growth in macrophages and epithelial cells, and virulence in mice. Moreover, it was demonstrated that OxyR regulates the expression of the $\operatorname{ahpC}, k a t G$, and $\operatorname{sodB}$ genes, with the most pronounced regulatory effect exerted on $a h p C$.

A more thorough understanding of the $F$. tularensis antioxidant system will undoubtedly reveal virulence mechanisms of this bacterium, since ROS constitute such an essential threat to the pathogen. As aforementioned, antioxidant enzymes, such as catalase, AhpC, SodC, and SodB, all contribute to the virulence of $F$. tularensis in mice, although each appears to render the bacterium only moderately attenuated and this indicates that the antioxidant system of F. tularensis is complex and may in part possess overlapping functions (Lindgren et al., 2007; Ma et al., 2016). Indeed, a double deletion mutant of $k a t G$ and $a h p C$ has not been possible to generate in F. tularensis (Binesse et al., 2015) and this demonstrates that the cooperative functions of these enzymes are crucial, although either one is not essential. The aim of the present study was to better understand this interconnecting web of antioxidants in F. tularensis. To this end, a double deletion mutant, $\Delta o x y R / \Delta k a t G$, was generated since this mutant, besides lack of catalase activity, should have a repressed expression of OxyR-regulated antioxidant genes, one of which is AhpC (Ma et al., 2016). We hypothesized that the lack of both KatG and OxyR would lead to a severely impaired phenotype of $F$. tularensis LVS. We therefore characterized the phenotypes of single deletion mutants, $\Delta o x y R$ and $\Delta k a t G$, and a double deletion mutant, $\Delta o x y R / \Delta k a t G$, in comparison to the parental LVS strain.

\section{MATERIALS AND METHODS}

\section{Bacterial Strains}

The F. tularensis LVS strain was obtained from the Francisella strain collection (FSC) at FOI, Swedish Defense Research Agency. The kat $G$ deletion mutant $(\Delta k a t G)$ has been described previously (Lindgren et al., 2007).

The $\triangle o x y R$ and $\Delta o x y R / \Delta k a t G$ mutants of the LVS strain were generated by allelic replacement as described previously (Golovliov et al., 2003). Briefly, sequences up- and down-stream of oxyR were amplified by PCR. The fragments contained complementary sequences, which were joined together by a second PCR. The resulting fragment was cloned into the pDM4 suicide-vector, which was transformed into Escherichia coli S17$\lambda$ pir and thereafter transferred to LVS by conjugation. Clones with a successful recombination event were selected on plates supplemented with $\mathrm{Cm}$ and polymyxin $\mathrm{B}$. Correct integration was confirmed by PCR. Positive clones were subjected to sucrose 
selection to select for a second recombination event and clones were screened by PCR to identify successful deletion mutants. The double deletion mutant $\Delta o x y R / \Delta k a t G$ was generated using the same procedure, apart from using the pDMK3 plasmid carrying kanamycin resistance. The deletions were verified by sequencing $1500 \mathrm{bp}$ on each side of the deleted region.

\section{Aerobic and Microaerobic Growth}

Bacteria were cultivated overnight on plates based on modified $\mathrm{GC}$-agar (MC plates) and then inoculated to an $\mathrm{OD}_{600}$ of 0.1 in Chamberlain's chemically defined medium (CDM). All cultures were split into triplicates and were incubated at $37^{\circ} \mathrm{C}$ and 200 $\mathrm{rpm}$ in an aerobic (normal air) or a microaerobic $\left(10 \% \mathrm{O}_{2}\right.$ and $10 \% \mathrm{CO}_{2}$ ) milieu up to $48 \mathrm{~h}$ with monitoring of the $\mathrm{OD}_{600}$.

\section{$\mathrm{H}_{2} \mathrm{O}_{2}$ Susceptibility Assay}

Bacteria were cultivated overnight on MC plates, inoculated to an $\mathrm{OD}_{600}$ of 0.1 in $\mathrm{CDM}$ and $\mathrm{H}_{2} \mathrm{O}_{2}$ was added to the final concentration of $0.02,0.1$, or $0.5 \mathrm{mM}$, respectively. Controls were grown without the addition of $\mathrm{H}_{2} \mathrm{O}_{2}$. All cultures were split into triplicates and were incubated at $37^{\circ} \mathrm{C}$ and $200 \mathrm{rpm}$ up to $24 \mathrm{~h}$ with monitoring of the $\mathrm{OD}_{600}$.

\section{Catalase Activity Assay}

Catalase degrades $\mathrm{H}_{2} \mathrm{O}_{2}$ to $\mathrm{O}_{2}$ and $\mathrm{H}_{2} \mathrm{O} \cdot \mathrm{H}_{2} \mathrm{O}_{2}$ absorbs light at $240 \mathrm{~nm}$ and degradation of $\mathrm{H}_{2} \mathrm{O}_{2}$ can therefore be measured as a reduction of $\mathrm{A}_{240} \mathrm{~nm}$ over time.

Strains were cultivated overnight after being diluted to an $\mathrm{OD}_{600}$ of 0.1 in CDM. For each strain, one set of tubes were left untreated and another set of tubes were supplemented with $\mathrm{H}_{2} \mathrm{O}_{2}$ to a final concentration of $0.02,0.1$, or $0.2 \mathrm{mM}$. All cultures were split into triplicates and incubated at $37^{\circ} \mathrm{C}, 200 \mathrm{rpm}$ for 2 , 4 , and $24 \mathrm{~h}$ before sampling for evaluation of catalase activity. Depending on the density and growth phase of the culture, a volume of 10-50 $\mu$ l were withdrawn and diluted in PBS to reach a final volume of $120 \mu \mathrm{l}$ in UV-clear 96-well plates (Greiner Bioone, Frickenhausen, Germany). Then, $80 \mu \mathrm{l} 100 \mathrm{mM} \mathrm{H}_{2} \mathrm{O}_{2}$ in PBS was added to each sample immediately before placing the plate in a Tecan Infinite 200 pro plate reader and measuring the reduction in absorption at $240 \mathrm{~nm}$ for $10 \mathrm{~min}$. A molar extinction coefficient of $\mathrm{H}_{2} \mathrm{O}_{2}$ at $240 \mathrm{~nm}$ of $43.6 \mathrm{M}^{-1} \mathrm{~cm}^{-1}$ was used to calculated the concentration of $\mathrm{H}_{2} \mathrm{O}_{2}$ using the Beer-Lambert law, $A=\varepsilon c l$. One unit of catalase is defined as the amount that decomposes $1 \mu \mathrm{mol}$ of $\mathrm{H}_{2} \mathrm{O}_{2}$ per minute per $\mathrm{OD}_{600}$ at $25^{\circ} \mathrm{C}$. The catalase units were normalized against the OD of the culture.

\section{Paraquat Susceptibility Assay}

Susceptibility of $F$. tularensis strains to $\mathrm{O}_{2}^{-}$was determined by use of the $\mathrm{O}_{2}^{-}$generating compound paraquat dichloride hydrate (Sigma-Aldrich, St. Louis, USA) in a disc diffusion assay. Paraquat generates $\mathrm{O}_{2}^{-}$through reacting with parts of the respiratory chain in bacteria, causing the reduction of $\mathrm{O}_{2}$ to $\mathrm{O}_{2}^{-}$ (Hassan and Fridovich, 1979). Bacterial strains were cultivated on MC plates overnight, re-suspended in phosphate-buffered saline (PBS) and approximately $3 \times 10^{5} \mathrm{CFU}$ were plated onto MC plates. Sterile filter discs (Oxoid Blank Antimicrobial Susceptibility Discs, Thermo Scientific, MA, USA) were placed in the center the plates once they had dried, and $10 \mu \mathrm{l}$ of MQwater, $1.25 \mathrm{mM}, 5 \mathrm{mM}$ or $20 \mathrm{mM}$ paraquat solution was added to each disc. The plates were incubated for 4 days at $37^{\circ} \mathrm{C}, 5 \% \mathrm{CO}_{2}$ before the size of the growth inhibition zone surrounding each disc was determined.

\section{Peroxynitrite Susceptibility Assay}

3-morpholinosydnonimine hydrochloride (SIN-1) (Molecular Probes, Oregon, USA) spontaneously releases (NO) and $\mathrm{O}_{2}^{-}$ under physiological conditions, thereby generating peroxynitrite $\left(\mathrm{ONOO}^{-}\right)$. Under physiological conditions $1 \mathrm{mM}$ SIN-1 generates $10 \mu \mathrm{M} \mathrm{ONOO}^{-} / \mathrm{min}$ (Lindgren et al., 2007).

Strains were cultivated in CDM to logarithmic growth phase and diluted to a density of approximately $2 \times 10^{6} \mathrm{bacteria} / \mathrm{ml}$ in PBS. The bacterial suspensions were incubated with or without the addition of $0.48 \mathrm{mM}$ SIN-1 with equal amounts of SIN-1 added at the start of the experiment and again after $1.5 \mathrm{~h}$ to ensure stable levels of $\mathrm{ONOO}^{-}$(Lindgren et al., 2005). After $3 \mathrm{~h}$ samples were collected, diluted and plated on MC plates for determination of viable bacteria.

\section{Analysis of Gene Expression by Real Time PCR}

Bacteria were cultivated overnight on MC plates, inoculated to an $\mathrm{OD}_{600}$ of 0.1 in $\mathrm{CDM}$ and incubated at $37^{\circ} \mathrm{C}, 5 \% \mathrm{CO}_{2}$ for $10 \mathrm{~h}$ before sampling. RNA extraction, cDNA synthesis and Real Time PCR (RT-PCR) were all performed as described previously (Honn et al., 2012).

Briefly, RNA was extracted using Trizol reagent (Invitrogen, CA, USA) from pelleted bacteria, $3 \times 10^{9} \mathrm{CFU} /$ sample. Contaminating DNA was removed using the DNA-free kit (Ambion, Inc, Austin, TX, USA) and RNA was quantified by Nanodrop (Thermo Fisher Scientific, Wilmington, DE, USA). cDNA was synthesized from $1 \mu \mathrm{g}$ RNA/sample using iScript (BioRad, Hemel, Hampstead, UK), RT-PCR was performed using the Power SYBR green PCR Master Mix (Applied Biosystems, Foster City, CA, USA) and the ABI Prism 7900Ht Sequence Detection System (Applied Biosystems) as described (Honn et al., 2012). Trizol, DNA-free, iScript and Power SYBR green were all used in accordance with the instructions provided by the manufacturers. Forward and reverse primers were obtained from Invitrogen and have been published previously for $f_{s l A}$ (FTL_1832), fslB (FTL_1833), fslC (FTL_1834), fslD (FTL_1835), fslE (FTL_1836), fupA (FTL_0439), furA (FTL_1831), (Lindgren et al., 2009), tul4, iglC (FTL_0113), (Bröms et al., 2009), mglA (FTL_0260), feoB (FTL_0133), and katG (FTL_1504) (Honn et al., 2012), sequences for, grxA (FTL_0985), grxB (FTL_1792), gpx (FTL_1383), sspA (FTL_1606), ahpC1 (FTL_0542), ahpC2 (FTL_1191), sodB (FTL_0380), sodC (FTL_1791), clpB (FTL_0094), groES (FTL_1715), groEL (FTL_1714), and dnaK (FTL_1191) are available upon request.

The Ct values of the selected genes were normalized to the Ct value of the house keeping gene FTT0901 (lpnA) and relative copy numbers ( $\mathrm{RCN}$ ) were calculated according to the following equation: $\mathrm{RCN}=2^{-\Delta \mathrm{Ct}} \times 100$, where $\Delta \mathrm{Ct}$ is Ct(target)-Ct(FTT0901) (Gavrilin et al., 2006). Thus, the copy 
number of a given gene is related to the copy number of FTT0901. Normalized Ct values were used for statistical evaluation of the data by One way ANOVA followed by Tukey's honest significant difference (HSD).

\section{Preparation and Infection of BMDM}

The capacity of LVS and the mutants to proliferate intracellularly were assessed in bone marrow-derived macrophages (BMDMs). BMDMs were generated from $\mathrm{C} 57 \mathrm{BL} / 6$ mice essentially as described previously (Bröms et al., 2011).

The day before infection, BMDM cells were seeded at a density of $4 \times 10^{5}$ cells $/ \mathrm{ml}$ in 24 -well tissue-culture plates and incubated at $37^{\circ} \mathrm{C}, 5 \% \mathrm{CO}_{2}$ with or without murine recombinant $1000 \mathrm{U} / \mathrm{ml}$ of IFN- $\gamma$ (Peprotech, Rocky Hill, NJ, USA) The next day, the cells were washed and reconstituted with fresh, prewarmed culture media. Bacteria were grown overnight on MC plates and re-suspended in PBS to a density of approximately $3 \times 10^{9}$ bacteria $/ \mathrm{ml}$. Bacteria were diluted in DMEM and added to each well at multiplicity of infection of 30 and bacterial uptake was allowed to occur for $90 \mathrm{~min}$ at $37^{\circ} \mathrm{C}, 5 \% \mathrm{CO}_{2}$. Remaining extracellular bacteria were removed by rinsing the monolayers three times with DMEM and incubating with gentamicin for 45 min followed by rinsing the monolayers three times. This time-point was defined as $0 \mathrm{~h}$. After 0,4 and $24 \mathrm{~h}$ incubation the macrophages were lysed in $0.1 \%$ deoxycholate in PBS. The lysate were serially diluted in PBS and plated on MC plates for determination of viable bacteria.

\section{Mouse Experiments}

Virulence of the mutant strains was determined by subcutaneous infection of female C57BL/6 mice with $4 \times 10^{3} \mathrm{CFU} /$ mouse of LVS, $\Delta o x y R, \Delta k a t G$, and $\Delta o x y R / \Delta k a t G$. Mice were monitored for signs of illness and were euthanized by inhalation of isoflurane followed by $\mathrm{CO}_{2}$ asphyxiation after 3 or 6 days, whereupon the number of viable bacteria in spleens and livers were determined by homogenizing the organs in PBS and plating dilutions on MC plates. All animal experiments were approved by the Local Ethical Committee on Laboratory Animals, Umeå, Sweden (no. A 1-09, A 99-11, and A 67-14).

\section{Statistical Analysis}

One way ANOVA followed by Tukey's HSD test was used to determine statistical significant difference between groups.

\section{RESULTS}

\section{Growth under Aerobic vs. Microaerobic Conditions}

CDM effectively supports growth of LVS. We therefore compared growth of the bacterial strains, LVS, $\Delta o x y R, \Delta k a t G$, and $\Delta o x y R / \Delta k a t G$. The former three strains all replicated to the same extent, whereas $\Delta o x y R / \Delta k a t G$ showed intact growth to late log phase, but impaired growth thereafter. Therefore, it did not reach as high densities as LVS and the other strains at $24 \mathrm{~h}$ ( $P<0.001$; Figure 1A). To explore if a reduced oxygen tension could rescue the growth of $\Delta$ oxyR/ $\Delta k a t G$, the strains were cultivated under microaerobic conditions, i.e., $10 \% \mathrm{O}_{2}$ and

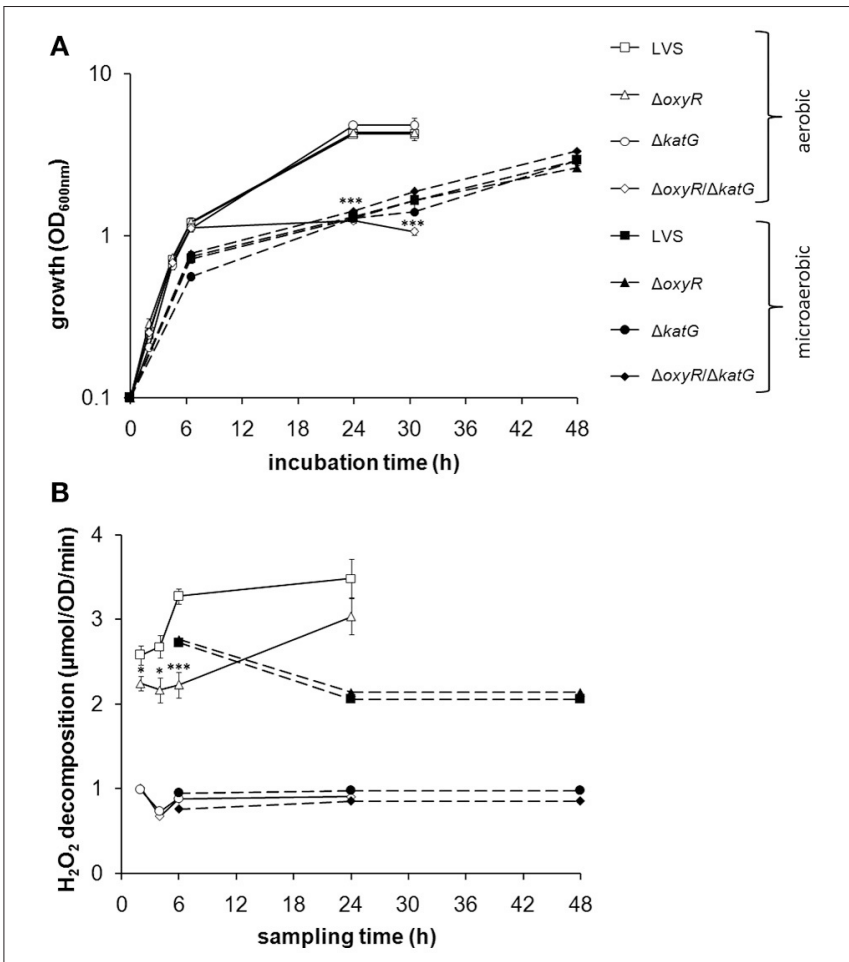

FIGURE 1 | (A) Growth of F. tularensis strains in CDM under aerobic or microaerobic conditions and $(\mathbf{B})$ catalase activity of the strains at indicated time-points during growth. (A) Shows a representative experiment of at least three performed and $\mathbf{( B )}$ the average from six to nine separate observations for each time point and growth condition. Error bars represent the SEM. ${ }^{*} P<$ $0.05,{ }^{\star \star \star} P<0.001$ vs. LVS.

$10 \% \mathrm{CO}_{2}$. Indeed, $\Delta o x y R / \Delta k a t G$ grew as well as the other strains and reached an optical density of $>2.0$ within $48 \mathrm{~h}$ (Figure 1A). As noted before (Honn et al., 2012), the growth rate of LVS under microaerobic conditions was reduced compared to aerobic conditions (Figure 1A).

\section{Catalase Activity under Aerobic vs. Microaerobic Conditions}

The results so far suggested that LVS experienced oxidative stress during growth in an aerobic environment and to handle this stress, required either the function of catalase, or the expression of OxyR-regulated detoxifying mechanisms. OxyR is known to respond to oxidative stress by inducing antioxidant enzymes, such as catalase. As an indicator of oxidative stress and to investigate if catalase is under the regulation of $o x y \mathrm{R}$ in LVS, we measured the activity of the enzyme during growth of the bacteria in CDM. The catalase activity in LVS gradually increased during the two to $24 \mathrm{~h}$ period, whereas the catalase activity in $\triangle o x y R$ was sustained at a constant, but lower level compared to LVS from two to six h $(P<0.05$ at 2 and $4 \mathrm{~h}$ and $P<0.001$ at $6 \mathrm{~h}$; Figure 1B). However, the catalase activity of the two strains was similar at $24 \mathrm{~h}$ (Figure 1B). In the microaerobic environment, the catalase activity of LVS and $\triangle o x y R$ was similar, but for both lower than in the aerobic environment (Figure 1B). The $\mathrm{H}_{2} \mathrm{O}_{2}$ 
decomposition in samples containing $\Delta k a t G$ or $\Delta o x y R / \Delta k a t G$ was below $1 \mu \mathrm{mol}$, regardless of growth condition and time point, indicating the absence of catalase activity (Figure 1B).

In summary, $\triangle o x y R$ demonstrated a basal catalase activity, but did not induce this activity further during the aerobic logarithmic growth phase as LVS did. $\Delta o x y R / \Delta k a t G$, which lacks this basal catalase activity, failed to grow to high densities under the aerobic condition, but grew as well as LVS in the microaerobic milieu.

\section{$\mathrm{H}_{2} \mathrm{O}_{2}$ Tolerance}

$\triangle o x y R$ and $\Delta k a t G$ grew as well as LVS in CDM despite the reduced, or lack of catalase activity (Figure $2 \mathrm{~A}$ ). To investigate their adaptation to stress, $\mathrm{H}_{2} \mathrm{O}_{2}$, the substrate of catalase, was added to the cultures. Growth of LVS or $\Delta o x y R$ was not affected by $0.02 \mathrm{mM} \mathrm{H}_{2} \mathrm{O}_{2}$, whereas, initially, the growth rate of $\Delta k a t G$ was reduced $(P<0.01)$ and growth of $\Delta$ oxyR/ $\Delta k a t G$ almost

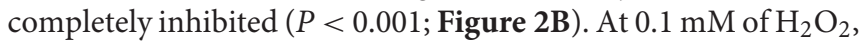
LVS and $\triangle o x y R$ still grew rapidly, in contrast to $\Delta k a t G$ and $\Delta o x y R / \Delta k a t G$ that did not grow at all $(P<0.001$; Figure $2 \mathrm{C})$. Growth of $\triangle o x y R$ was significantly reduced in the presence of 0.5 $\mathrm{mM}$ of $\mathrm{H}_{2} \mathrm{O}_{2}$ compared to LVS $(P<0.001$; Figure $2 D)$. Exposure of the strains to $\mathrm{H}_{2} \mathrm{O}_{2}$ did not significantly change their catalase activity (data not shown).

In summary, the mutant strains displayed increased susceptibility to $\mathrm{H}_{2} \mathrm{O}_{2}$ as compared to LVS, with the effect being most pronounced for $\Delta o x y R / \Delta k a t G$, followed by $\Delta k a t G$, and the least affected strain being $\triangle o x y R$.

\section{Susceptibility to Paraquat-Mediated Killing}

$\mathrm{O}_{2}^{-}$is continuously generated as a by-product of the respiratory chain during growth of bacteria. To investigate the capacity of the bacteria to defend against such ROS, LVS, $\Delta o x y R, \Delta k a t G$, and $\Delta o x y R / \Delta k a t G$ were exposed to paraquat in a disc diffusion assay (Figure 3). Paraquat dichloride hydrate generates $\mathrm{O}_{2}^{-}$through a reaction with parts of the respiratory chain in bacteria, causing the reduction of $\mathrm{O}_{2}$ to $\mathrm{O}_{2}^{-}$(Hassan and Fridovich, 1979). $\Delta o x y R$ displayed a significantly larger zone of inhibition than did LVS in the presence of 1.25 and $5 \mathrm{mM}$ paraquat $(P<0.001$ and 0.01 , respectively), but the zones were similar when exposed to $20 \mathrm{mM}$ (Figure 3). The zone of inhibition for $\Delta k a t G$ was larger compared to LVS at $1.25 \mathrm{mM}(P<0.05)$, but similar at the two higher concentrations (Figure 3). A significantly larger zone of inhibition was observed for $\Delta o x y R / \Delta k a t G$ vs. LVS and $\Delta k a t G$ at

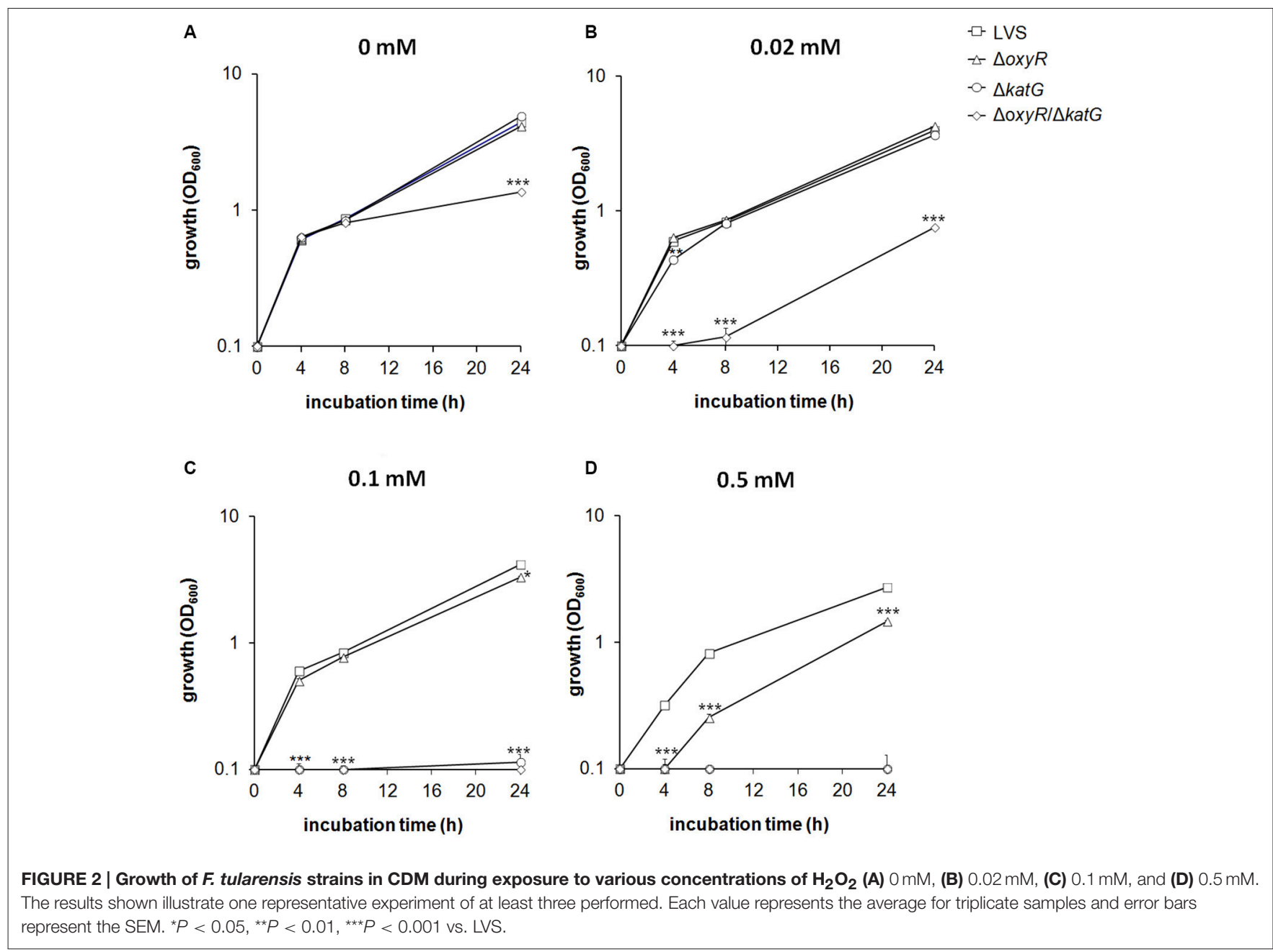




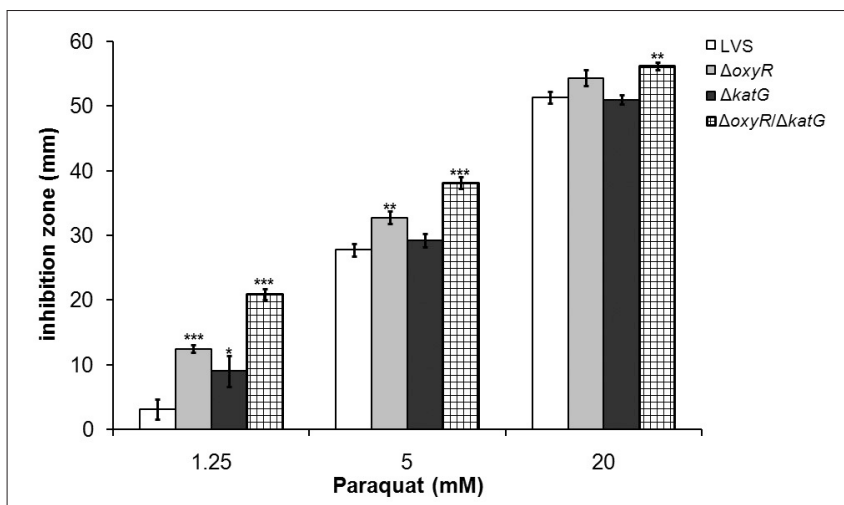

FIGURE 3 | $\boldsymbol{F}$. tularensis strains were exposed to the $\mathrm{O}_{2}^{-}$-generating compound paraquat in a disc diffusion assay. Each bar represents the average from three separate experiments with triplicate samples in each and error bars represent the SEM. ${ }^{\star} P<0.05,{ }^{\star \star} P<0.01,{ }^{\star \star *} P<0.001$ vs. LVS for each concentration. all three concentrations of paraquat $(P<0.001$ for 1.25 and $5 \mathrm{mM}$ and $P<0.01$ for $20 \mathrm{mM}$ ) and also larger compared to $\triangle o x y R$ at 1.25 and $5 \mathrm{mM}(P<0.01$; Figure 3$)$.

In summary, the results demonstrated that $\triangle o x y R$ and $\Delta o x y R / \Delta k a t G$ were more susceptible to paraquat-mediated killing compared to LVS, with $\Delta o x y R / \Delta k a t G$ being the most susceptible, whereas $\Delta k a t G$ was only slightly more susceptible than LVS.

\section{Susceptibility to SIN-1-Mediated Killing}

Peroxynitrite $\left(\mathrm{ONOO}^{-}\right)$is a highly reactive and bactericidal ROS formed through the reaction between $(\mathrm{NO})$ and $\mathrm{O}_{2}^{-}$and it is active against $F$. tularensis in activated macrophages (Lindgren et al., 2005). Experimentally, SIN-1 can be used to mimic a continuous exposure to $\mathrm{ONOO}^{-}$. SIN-1 slowly decomposes, thereby releasing both $\mathrm{NO}$ and $\mathrm{O}_{2}^{-}$that combine to form $\mathrm{ONOO}^{-}$, which quickly is internalized since it passes through lipid bilayers (Hogg et al., 1992; Murphy et al., 1998).

The exposure to $0.48 \mathrm{mM} \mathrm{SIN-1}$ for $3 \mathrm{~h}$ reduced the viability of all strains in comparison to un-treated cultures $(P<0.001$ for all strains), but affected the mutant strains to a greater extent compared to LVS ( $P<0.001$ vs. LVS for all; Figure 4). The viability of LVS decreased approximately $0.8 \log _{10}$, of $\Delta o x y R 2.8$ $\log _{10}$, of $\Delta k a t G 3.0 \log _{10}$, and of $\Delta o x y R / \Delta k a t G 4.6 \log _{10} \mathrm{CFU}$. The latter was significantly more susceptible than any of the other strains $(P<0.001$; Figure 4$)$.

In summary, all mutant strains displayed increased susceptibility to $\mathrm{ONOO}^{-}$as compared to LVS, with the effect being similar for $\Delta o x y R$ and $\Delta k a t G$ and most pronounced for $\Delta o x y R / \Delta k a t G$.

\section{Gene Expression}

$\Delta o x y R / \Delta k a t G$ did not grow after the late logarithmic growth phase (Figure 1A), and we therefore found it of interest to explore the gene expression of the strains at $10 \mathrm{~h}$, i.e., during the late logarithmic growth phase. The analysis was focused on genes expressing proteins influencing the oxidative stress response of

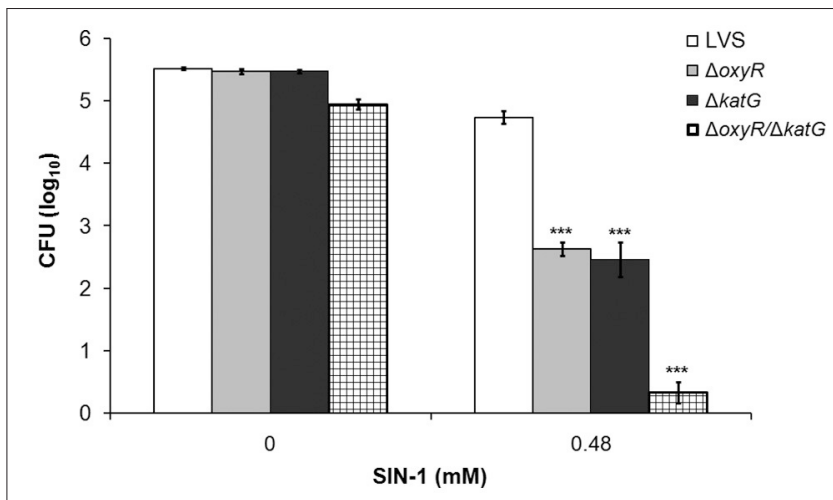

FIGURE 4 | F. tularensis strains were exposed to the peroxynitrite generating compound $\mathbf{S I N}-\mathbf{1}$ for $\mathbf{3} \mathbf{h}$. After $1.5 \mathrm{~h}$ of incubation, additional $\mathrm{SIN}-1$ was added to the tubes to ensure a constant generation of peroxynitrite during the whole incubation period. Each bar represents the average from three separate experiments with triplicate samples in each and error bars represent the SEM. ${ }^{\star * \star} P<0.001$ vs. LVS

the bacterium, such as antioxidant enzymes, chaperones and iron-related proteins. Genes found to be differentially expressed vs. LVS are shown in Figure 5. Of all genes examined, ahpC was the sole gene significantly repressed in $\triangle$ oxyR $(P<0.001$; Figure 5A). A similar degree of repression, about 3-fold, was observed in $\Delta o x y R / \Delta k a t G$, which in addition, had a 1.5 to 2 -fold increased expression of $\operatorname{sodB}, \operatorname{sod} C$ and FTT0086 $(P<0.001$ for all genes; Figure 5A). $a h p C$ was not repressed in $\Delta k a t G$ and as expected, $k a t G$ transcripts were not detected in either $\Delta k a t G$ or in $\Delta o x y R / \Delta k a t G$ (Figure 5A). All chaperone genes examined were upregulated 1.6 to 2.5 -fold in $\triangle$ oxyR and $\Delta$ kat $G(P<0.001$ for all genes; Figure 5B). In contrast, these genes, except for $c l p B$, were suppressed 2.4 to 3.1 -fold in $\Delta$ oxyR/ $\Delta k a t G(P<0.001$ for all genes).

$f_{s l}$, the first gene of the siderophore operon, was slightly upregulated in $\triangle o x y R$ and $\triangle k a t G$, although only about 1.2 -fold, whereas the other iron-related genes were expressed at similar levels as in LVS. In contrast, $f$ slA was suppressed 1.8 -fold in $\Delta o x y R / \Delta k a t G$ and $f s l E, f s l F$ and $f e o B$ were upregulated 2.5 to 2.9-fold ( $P<0.001$; Figure 5C).

In summary, the absence of OxyR resulted in a suppressed expression of $a h p C$ and an up-regulated expression of genes encoding chaperone proteins. Except for $a h p C$, the expression profile of $\Delta k a t G$ was similar to $\triangle o x y R$. In contrast, loss of both oxy $R$ and $k a t G$ changed the expression profile and low expression of chaperone-encoding genes was observed in $\Delta$ oxy $R / \Delta k a t G$, together with high expression of antioxidant genes, except for $a h p C$ and $k a t G$, and an altered expression of genes related to iron-uptake.

\section{Intracellular Replication in BMDM}

Based on the increased susceptibility to various ROS displayed by $\Delta o x y R, \Delta k a t G$, and $\Delta o x y R / \Delta k a t G$, it was of interest to test whether the strains were defective for replication in professional phagocytes. Non-stimulated or IFN- $\gamma$-stimulated BMDMs were infected with LVS, $\Delta o x y R, \Delta k a t G$, or $\Delta o x y R / \Delta k a t G$ at an MOI 


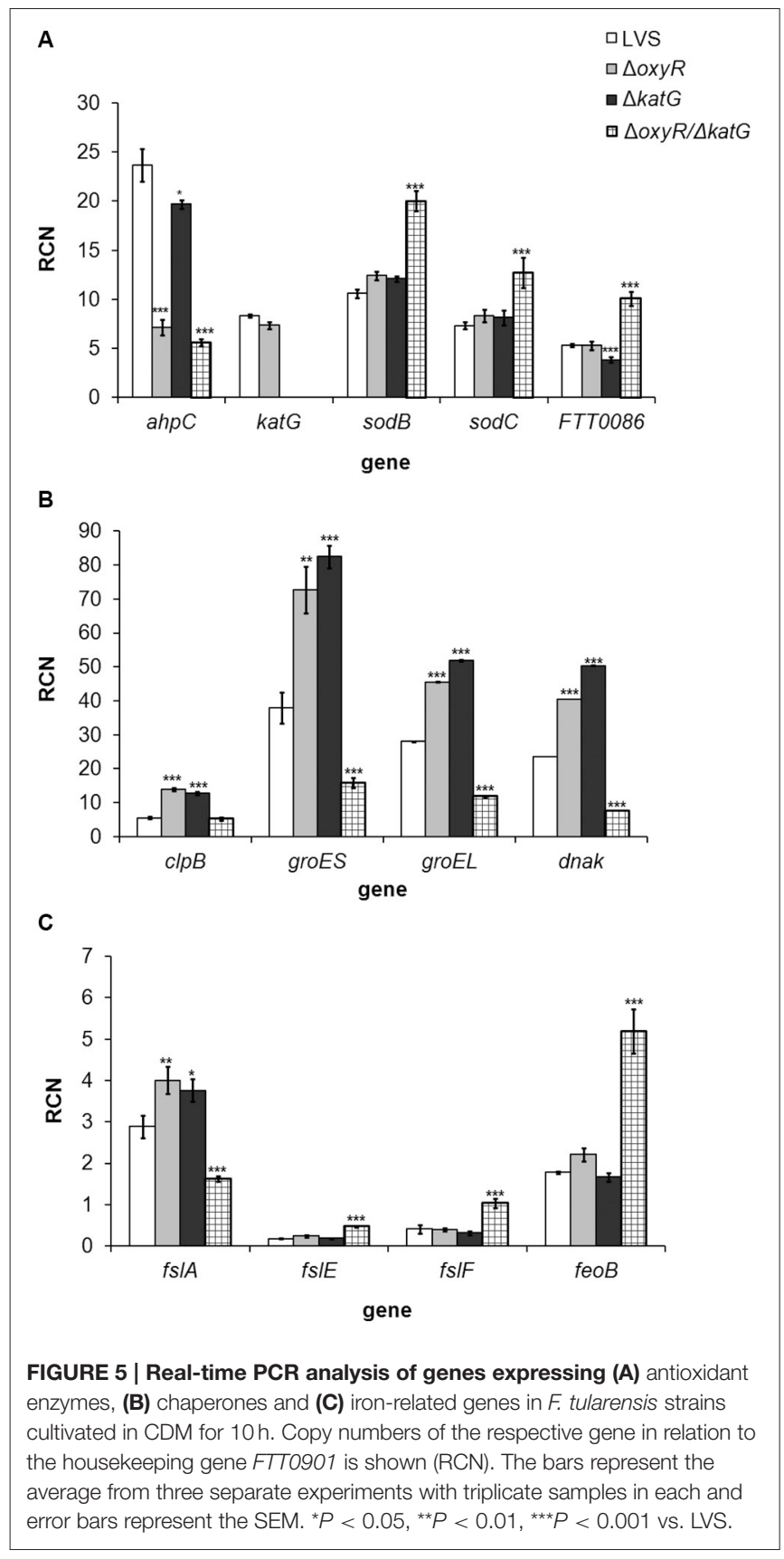

of 30 , and the viability of internalized bacteria was determined after $0 \mathrm{~h}, 4 \mathrm{~h}$, and $24 \mathrm{~h}$. In non-stimulated BMDM, LVS grew from approximately $2.5 \log _{10}$ CFU to more than $5.0 \log _{10} \mathrm{CFU}$ within $24 \mathrm{~h}$ and also $\triangle o x y R$ and $\triangle k a t G$ grew to similar extent (Figure 6A). $\Delta$ oxyR/ $\Delta$ kat $G$ grew in non-stimulated cells, but reached approximately 10 -fold lower numbers compared to the other strains after $24 \mathrm{~h}(P<0.001$; Figure 6A).

IFN- $\gamma$-stimulation of BMDM prior to infection reduced the numbers of LVS, $\Delta k a t G$, and $\Delta o x y R$ about 10 -fold at $24 \mathrm{~h}$ vs. the numbers in non-stimulated cultures $(P<0.001$; Figures $6 \mathbf{A}, \mathbf{B})$. There was no growth of $\Delta o x y R / \Delta k a t G$ in IFN- $\gamma$-stimulated cultures and, thus, significantly lower bacterial

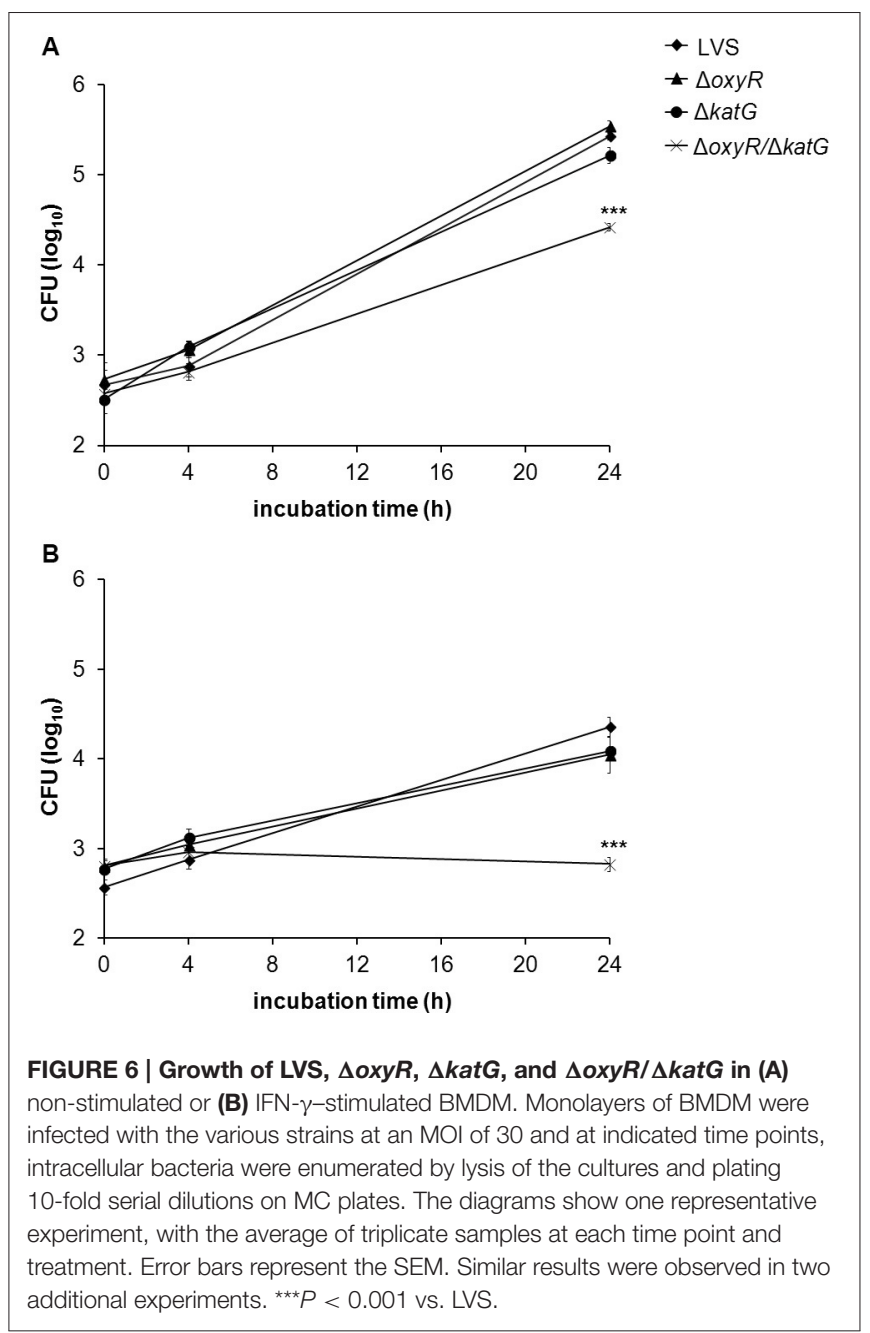

numbers compared to non-stimulated cultures at $24 \mathrm{~h}(P<0.001$; Figures 6A,B) and vs. all the other strains exposed to IFN- $\gamma$ $(P<0.001$; Figure 6B).

Thus, the $\Delta o x y R$ and $\Delta k a t G$ mutants showed intact capacity of intracellular replication, whereas the $\Delta o x y R / \Delta k a t G$ mutant showed impaired replication in BMDM, both in the presence and absence of IFN- $\gamma$.

\section{Virulence in Mice}

The virulence of LVS, $\Delta o x y R, \Delta k a t G$, and $\Delta o x y R / \Delta k a t G$ was determined by subcutaneous infection of C57BL/6 mice with $4 \times 10^{3} \mathrm{CFU} / \mathrm{mouse}$, a non-lethal dose, and enumeration of viable bacteria in spleen and liver on day 3 and 6 of infection. Compared to LVS, there were lower numbers of both $\triangle o x y R$ and $\Delta k a t G$ on day 3 in the liver of the mice $(P<0.05$; Figure $7 \mathrm{~A})$, whereas there were no differences between these strains in either the liver or spleen at the other time points (Figures 7A,B). Numbers of $\triangle o x y R / \Delta k a t G$ in both organs were at least 100fold lower vs. all other strains at both time points $(P<0.001)$. Thus, both $\Delta o x y R$ and $\Delta k a t G$ showed slight attenuation in mice, whereas $\Delta o x y R / \Delta k a t G$ was highly attenuated. 


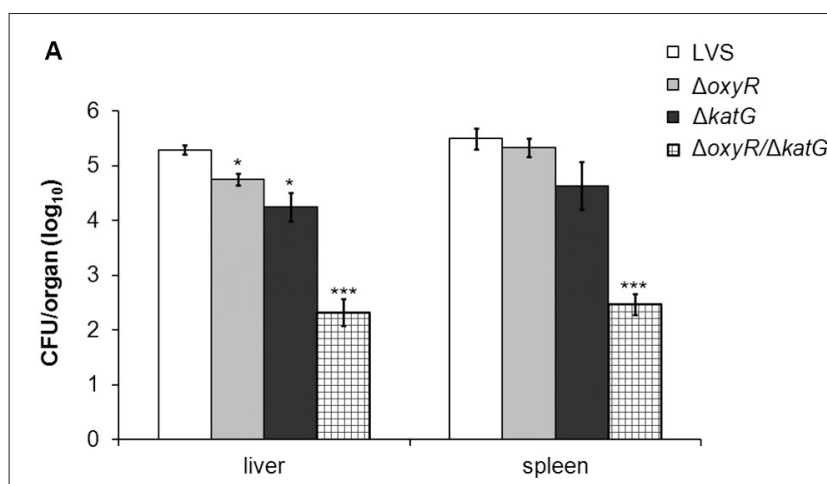

B

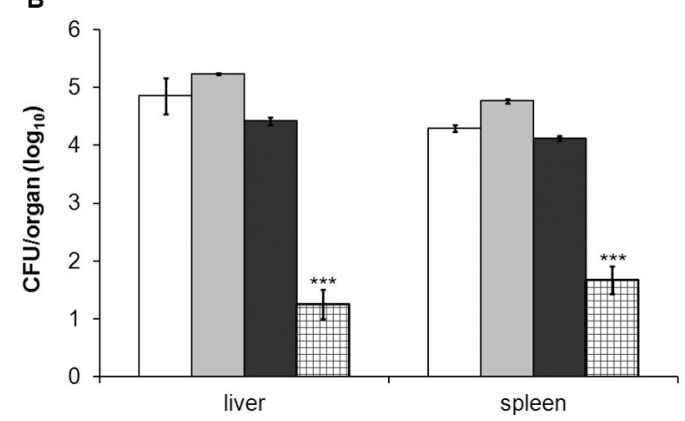

FIGURE 7 | Bacterial burden of mice at (A) 3 and (B) 6 days after subcutaneous inoculation of $4 \times 10^{3} \mathrm{CFU}$ of either LVS, $\triangle$ oxyR, $\Delta$ katG or $\Delta$ oxyR/ $\Delta$ katG. The average of four mice and SEM are shown. ${ }^{*} P<0.05$, ${ }^{\star \star \star} P<0.001$ vs. LVS.

\section{DISCUSSION}

Francisella tularensis is a versatile bacterium capable of surviving in many different hosts, vectors and in various cell types, including the normally bactericidal macrophages. Upon phagocytosis, F. tularensis is encased in a phagosome, a membrane-bound compartment designed for the annihilation of phagocytosed microbes, which is rich in antimicrobial molecules, such as reactive oxygen and nitrogen species. Although F. tularensis only transiently resides in this compartment, it must still muster defenses against highly reactive species in order to survive and escape to the cytosol, where it proceeds to replicate. By entering the cytosol, F. tularensis gains access to a nutrient-rich, protected niche in which it multiplies. As survival and replication in the intracellular niche is essential for the life cycle of F. tularensis, a thorough understanding of how the bacterium survives intracellularly is essential to fully grasp its defense mechanisms against oxidative stress. To this end, the study focused on understanding the interplay between catalase and OxyR, the latter being important for the expression of several antioxidant enzymes, in the defense against ROS and their impact on the survival of the bacterium in professional phagocytes.

To investigate if OxyR is involved in the oxidative stress response of LVS, we constructed an in-frame deletion of $o x y R$. A similar investigation has been performed recently by $\mathrm{Ma}$ et al. which studied the role of OxyR in LVS (Ma et al., 2016).
It was found that OxyR controlled transcription of kat $G$ and the findings agree with the reduced catalase activity of $\triangle o x y R$ observed in the present study. Nevertheless, our study revealed that even in the absence of OxyR, there was still prominent catalase activity. Overall, it appears that OxyR, as expected, regulates $k a t G$ in the LVS strain, however, the regulation does not completely abolish its expression as is the case observed for various other bacterial species, e.g., E. coli (Michán et al., 1999), Salmonella enterica (Morgan et al., 1986), Haemophilus influenza (Whitby et al., 2012), or Moraxella catarrhalis (Hoopman et al., 2011). In both the present study, and in the previous study, it was observed that the lack of OxyR led to marked suppression of $a h p C 2$ (Ma et al., 2016). In addition Ma et al. demonstrated suppressed expression of both kat $G$ and $\operatorname{sodB}$ in $\triangle o x y R$ by realtime PCR and demonstrated that OxyR binds to the upstream promoter regions of each gene. In contrast, there was no downregulation of $k a t G$ or $s o d B$ observed in the present study. Likely, this is a consequence of the rapid on/off switch of the promoter binding capacity of OxyR in response to the oxidative levels in the bacteria leading to a limited window when elevated mRNA levels can be detected (Wei et al., 2012).

Besides antioxidant genes, our study revealed an aberrant expression of genes encoding chaperone proteins of the mutants. Such proteins are induced in response to various stresses, including oxidative stress (Hartl et al., 2011). Thus, the induced expression of these genes in $\Delta o x y R$ and in $\Delta k a t G$, also observed by Ma et al. (2016), likely is a reflection of oxidative stress encountered by the mutants. The chaperone network likely helps the bacterium to handle this stress through unfolding and/or degradation of mis-folded/damaged proteins. The reason behind the suppressed expression of multiple chaperone genes in $\Delta o x y R / \Delta k a t G$ is obscure, but should lead to an accumulation of damaged or mis-folded proteins and may explain why it was so impaired for growth in broth. The intact growth of $\Delta o x y R / \Delta k a t G$ under microaerobic conditions likely reflects that reduced levels of ROS are formed and therefore that antioxidant defenses are less important. The aberrant expression of genes related to iron-uptake did not result in a skewed iron content of $\Delta o x y R / \Delta k a t G$ (data not shown) and it is therefore not obvious that this would influence the susceptibility of the strain to various ROS.

The F. tularensis ahpC2 gene is divergently transcribed from the $o x y R$ promoter, a feature commonly seen for genes transcriptionally regulated by OxyR (Hahn et al., 2002; Maddocks and Oyston, 2008). AhpC belongs to the peroxiredoxin family, which is ubiquitously found in nature (Rhee et al., 2005) and is known to be involved in defenses against peroxides in E. coli (Storz et al., 1989), and both peroxides and peroxynitrite in, e.g., Salmonella typhimurium (Bryk et al., 2000), and in the defense against superoxide and peroxynitrite in the virulent SCHU S4 strain of F. tularensis subsp. tularensis (Binesse et al., 2015). In agreement with this, and in view of the reduced expression of $\mathrm{AhpC}$ in $\Delta \operatorname{oxy} R$, this mutant was also highly susceptible to $\mathrm{ONOO}^{-} . \Delta k a t G$ was as susceptible as $\triangle o x y R$ to $\mathrm{ONOO}^{-}$and in view of the substantial catalase activity remaining in $\Delta o x y R$, this result implies that the function of catalase overlaps with other OxyR-regulated detoxifying mechanisms, presumably AhpC, to 
protect against $\mathrm{ONOO}^{-}$. Further corroborating the importance of $\mathrm{AhpC}$ and catalase was the failure to generate a $k a t G$ and $a h p C$ double deletion mutant and even an $a h p C$ mutant in LVS. Hence, AhpC seems indispensable to LVS, which is in stark contrast to SCHU S4, where deletion of $a h p C$ resulted in only slight attenuation (Binesse et al., 2015). This indicates that there is a disparity regarding the importance of the enzyme between the SCHU S4 and LVS strains, possibly a factor that to some extent explains the difference in virulence between the strains, since it implies that the detoxifying mechanisms of SCHU S4 are much more elaborate. Nevertheless, as for LVS, it has not been possible to generate a $k a t G$ and $a h p C$ double deletion mutant of SCHU S4 (Kadzhaev et al., 2009; Binesse et al., 2015). Collectively, this indicates that the mechanisms of protection conferred by these enzymes may be overlapping and the lack of both is detrimental to the survival of both LVS and highly virulent $F$. tularensis strains.

Based on the failure to generate a $k a t G$ and $a h p C$ double deletion mutant and the marked suppression of $a h p C$ in the $\triangle \operatorname{oxy} R$ mutant, we hypothesized that the absence of OxyR together with the absence of catalase would severely disarm the capability of the bacterium to handle ROS. Indeed, we observed that the $\Delta$ oxyR/ $\Delta k a t G$ mutant was hyper-susceptible to $\mathrm{H}_{2} \mathrm{O}_{2}$, $\mathrm{ONOO}^{-}$, and $\mathrm{O}_{2}^{-}$; much more so than either $\Delta$ oxyR or $\Delta k a t G$. Collectively, the results demonstrate that the roles of OxyRregulated antioxidant enzymes and catalase overlap to protect LVS against various ROS. We find it likely that the reduced activity of catalase and expression of ahpC observed in oxyR contributed to the increased susceptibility of the mutant to $\mathrm{H}_{2} \mathrm{O}_{2}$, $\mathrm{O}_{2}^{-}$, and $\mathrm{ONOO}^{-}$through the increase of both Fenton-mediated toxicity and direct $\mathrm{O}_{2}^{-}-$and $\mathrm{ONOO}^{-}$-mediated damage. We further suggest that the reduced levels of AhpC together with the lack of catalase in the $\Delta o x y R / \Delta k a t G$ strain, despite an increased expression of $\operatorname{sodB}$, sodC and FTT0086, resulted in enhanced Fenton-mediated toxicity and $\mathrm{ONOO}^{-}$-mediated damage, which likely account for the extreme susceptibility of the double mutant to $\mathrm{O}_{2}^{-}, \mathrm{H}_{2} \mathrm{O}_{2}$, and $\mathrm{ONOO}^{-}$. Our findings concur with those of Ma et al. (2016), and, in addition, demonstrate that the combined activity of catalase and OxyR-regulated detoxifying mechanisms are critical for ROS detoxification by $F$. tularensis.

Despite the enhanced susceptibility of both $\Delta o x y R$ and $\Delta k a t G$ to various ROS, the strains replicated as efficiently as LVS in mouse BMDM, but importantly, the capacity to replicate in professional phagocytes required either OxyR or catalase, since $\Delta$ oxyR/ $\Delta k a t G$ failed to replicate. IFN- $\gamma$-activation of BMDM restricted growth of LVS, $\Delta k a t G$, and $\triangle o x y R$ to a similar degree and completely blocked the growth of $\Delta$ oxyR/ $\Delta k a t G$. The majority of $F$. tularensis LVS escapes the phagosome of IFN- $\gamma$-activated macrophages (Lindgren et al., 2004), but the mechanism of growth inhibition appears to vary depending on the cell model used (Edwards et al., 2010). IFN- $\gamma$-mediated inhibition of intracellular growth of $F$. novicida is dependent on the expression of IRGB10 and various guanylate-binding proteins (Meunier et al., 2015; Man et al., 2016), however, the role of this pathway is unknown for other F. tularensis species.
Our results reveal elaborate interconnecting roles between OxyR-regulated ROS-detoxifying mechanisms and catalase and demonstrate that either needs to be intact for the bacterium to thrive in professional phagocytes. The roles of the antioxidative mechanisms could be to protect the bacterium from direct damage by various ROS, such as $\mathrm{ONOO}^{-}$, which has been demonstrated to be crucial for killing of $F$. tularensis in peritoneal cells (Lindgren et al., 2005). Alternatively, or additionally, the antioxidants may restrict macrophage activation through their ability to preserve phosphatase activity required for kinase signaling and proinflammatory cytokine production (Melillo et al., 2010).

Our finding that $\triangle o x y R$ replicated as efficiently as LVS in BMDM is in contrast to findings in a previous study, which reported that an $o x y R$ mutant of LVS was markedly impaired with regard to escape from the phagosome, replication in professional phagocytes, and virulence in the mouse model (Ma et al., 2016). Notably, the LVS strain used by Ma et al. replicated less than 10-fold during $24 \mathrm{~h}$ in C57BL/6 BMDM, whereas the LVS strain used in the present study replicated about 500-fold. Isolates of LVS with different virulence are used in the research community (Griffin et al., 2015) and the distinct differences in the intracellular growth of these two LVS strains are additional examples of such distinct phenotypes. The phenotypic differences between the two LVS strains likely explain the discrepant findings of the two studies. The observation in the present study of the intact growth of the single mutants in BMDM was corroborated by findings in vivo, since the $\Delta o x y \mathrm{R}$ and $\Delta k a t \mathrm{G}$ mutants showed essentially intact growth in organs of mice, whereas $\Delta o x y \mathrm{R} / \Delta k a t \mathrm{G}$ hardly grew at all. Despite their effective growth in the organs, a previous study demonstrated a more distinct growth defect of the $\Delta k a t \mathrm{G}$ mutant, most likely because a 100 fold higher dose was given (Lindgren et al., 2007). Moreover, by the intranasal route, $\Delta o x y \mathrm{R}$ was demonstrated to be moderately attenuated (Ma et al.). Based on these collective findings, it can be concluded that both OxyR and KatG contribute to the virulence of F. tularensis LVS and that the concomitant loss is detrimental to the virulence of the bacterium.

Altogether, the results presented in this study clearly demonstrate the mutual importance of catalase and OxyR for a robust oxidative stress defense system and that either of these systems is vital for the intracellular replication of F. tularensis and for its virulence.

\section{AUTHOR CONTRIBUTIONS}

Conceived and designed the experiments: AS, MH, and HL. Performed the experiments: $\mathrm{MH}, \mathrm{HL}$, and GB. Analyzed the data: AS, MH, HL, and GB. Wrote the paper: HL, MH, and AS.

\section{ACKNOWLEDGMENTS}

Grant support was obtained from the Swedish Medical Research Council (K2010-9485, K2012-3469, and K2013-8621), and the Medical Faculty, Umeå University, Umeå, Sweden. 


\section{REFERENCES}

Andrews, S. C., Robinson, A. K., and Rodríguez-Quiñones, F. (2003). Bacterial iron homeostasis. FEMS Microbiol. Rev. 27, 215-237. doi: 10.1016/S01686445(03)00055-X

Anthony, L. S., Morrissey, P. J., and Nano, F. E. (1992). Growth inhibition of Francisella tularensis live vaccine strain by IFN-gamma-activated macrophages is mediated by reactive nitrogen intermediates derived from L-arginine metabolism. J. Immunol. 148, 1829-1834.

Bakshi, C. S., Malik, M., Regan, K., Melendez, J. A., Metzger, D. W., Pavlov, V. M., et al. (2006). Superoxide dismutase B gene (sodB)-deficient mutants of Francisella tularensis demonstrate hypersensitivity to oxidative stress and attenuated virulence. J. Bacteriol. 188, 6443-6448. doi: 10.1128/JB.00266-06

Betteridge, D. J. (2000). What is oxidative stress? Metab. Clin. Exp. 49, 3-8. doi: 10.1016/S0026-0495(00)80077-3

Binesse, J., Lindgren, H., Lindgren, L., Conlan, W., and Sjöstedt, A. (2015). Roles of reactive oxygen species-degrading enzymes of Francisella tularensis SCHU S4. Infect. Immun. 83, 2255-2263. doi: 10.1128/IAI.02488-14

Bröms, J. E., Lavander, M., Meyer, L., and Sjöstedt, A. (2011). IglG and IglI of the Francisella pathogenicity island are important virulence determinants of Francisella tularensis LVS. Infect. Immun. 79, 3683-3696. doi: 10.1128/IAI.01344-10

Bröms, J. E., Lavander, M., and Sjöstedt, A. (2009). A conserved alpha-helix essential for a type VI secretion-like system of Francisella tularensis. J. Bacteriol. 191, 2431-2446. doi: 10.1128/JB.01759-08

Bröms, J. E., Sjöstedt, A., and Lavander, M. (2010). The role of the Francisella tularensis pathogenicity island in type VI secretion, intracellular survival, and modulation of host cell signaling. Front. Microbiol.1:136. doi: $10.3389 /$ fmicb. 2010.00136

Bryk, R., Griffin, P., and Nathan, C. (2000). Peroxynitrite reductase activity of bacterial peroxiredoxins. Nature 407, 211-215. doi: 10.1038/35025109

Chong, A., and Celli, J. (2010). The Francisella intracellular life cycle: toward molecular mechanisms of intracellular survival and proliferation. Front. Microbiol. 1:138. doi: 10.3389/fmicb.2010.00138

Conlan, J. W. (2011). Tularemia vaccines: recent developments and remaining hurdles. Future Microbiol. 6, 391-405. doi: 10.2217/fmb.11.22

Edwards, J. A., Rockx-Brouwer, D., Nair, V., and Celli, J. (2010). Restricted cytosolic growth of Francisella tularensis subsp. tularensis by IFN-gamma activation of macrophages. Microbiology 156, 327-339. doi: $10.1099 /$ mic.0.031716-0

Farr, S. B., and Kogoma, T. (1991). Oxidative stress responses in Escherichia coli and Salmonella typhimurium. Microbiol. Rev. 55, 561-585.

Flannagan, R. S., Cosio, G., and Grinstein, S. (2009). Antimicrobial mechanisms of phagocytes and bacterial evasion strategies. Nat. Rev. Microbiol. 7, 355-366. doi: $10.1038 /$ nrmicro 2128

Fridovich, I. (1998). Oxygen toxicity: a radical explanation. J. Exp. Biol. 201, 1203-1209.

Gavrilin, M. A., Bouakl, I. J., Knatz, N. L., Duncan, M. D., Hall, M. W., Gunn, J. S., et al. (2006). Internalization and phagosome escape required for Francisella to induce human monocyte IL-1 $\beta$ processing and release. Proc. Natl. Acad. Sci. U.S.A. 103, 141-146. doi: 10.1073/pnas.0504271103

Golovliov, I., Sjöstedt, A., Mokrievich, A., and Pavlov, V. (2003). A method for allelic replacement in Francisella tularensis. FEMS Microbiol. Lett. 222, 273-280. doi: 10.1016/S0378-1097(03)00313-6

Griffin, A. J., Crane, D. D., Wehrly, T. D., and Bosio, C. M. (2015). Successful protection against tularemia in $\mathrm{C} 57 \mathrm{BL} / 6$ mice is correlated with expansion of Francisella tularensis-specific effector T cells. Clin. Vaccine Immunol. 22, 119-128. doi: 10.1128/CVI.00648-14

Hahn, J. S., Oh, S. Y., and Roe, J. H. (2002). Role of OxyR as a peroxide-sensing positive regulator in Streptomyces coelicolor A3(2). J. Bacteriol. 184, 5214-5222. doi: 10.1128/JB.184.19.5214-5222.2002

Hartl, F. U., Bracher, A., and Hayer-Hartl, M. (2011). Molecular chaperones in protein folding and proteostasis. Nature 475, 324-332. doi: 10.1038/nature 10317

Hassan, H. M., and Fridovich, I. (1979). Paraquat and Escherichia coli. Mechanism of production of extracellular superoxide radical. J. Biol. Chem. 254, 10846-10852.
Hogg, N., Darley-Usmar, V. M., Wilson, M. T., and Moncada, S. (1992). Production of hydroxyl radicals from the simultaneous generation of superoxide and nitric oxide. Biochem. J. 281, 419-424. doi: 10.1042/bj2810419

Honn, M., Lindgren, H., and Sjöstedt, A. (2012). The role of MglA for adaptation to oxidative stress of Francisella tularensis LVS. BMC Microbiol. 12:14. doi: $10.1186 / 1471-2180-12-14$

Hoopman, T. C., Liu, W., Joslin, S. N., Pybus, C., Brautigam, C. A., and Hansen, E. J. (2011). Identification of gene products involved in the oxidative stress response of Moraxella catarrhalis. Infect. Immun. 79, 745-755. doi: 10.1128/IAI.01060-10

Kadzhaev, K., Zingmark, C., Golovliov, I., Bolanowski, M., Shen, H., Conlan, W., et al. (2009). Identification of genes contributing to the virulence of Francisella tularensis SCHU S4 in a mouse intradermal infection model. PLoS ONE 4:e5463. doi: 10.1371/journal.pone.0005463

Lindgren, H., Honn, M., Golovlev, I., Kadzhaev, K., Conlan, W., and Sjöstedt, A. (2009). The 58-kilodalton major virulence factor of Francisella tularensis is required for efficient utilization of iron. Infect. Immun. 77, 4429-4436. doi: 10.1128/IAI.00702-09

Lindgren, H., Shen, H., Zingmark, C., Golovliov, I., Conlan, W., and Sjöstedt, A. (2007). Resistance of Francisella tularensis strains against reactive nitrogen and oxygen species with special reference to the role of KatG. Infect. Immun. 75, 1303-1309. doi: 10.1128/IAI.01717-06

Lindgren, H., Stenman, L., Tärnvik, A., and Sjöstedt, A. (2005). The contribution of reactive nitrogen and oxygen species to the killing of Francisella tularensis LVS by murine macrophages. Microbes Infect. 7, 467-475. doi: 10.1016/j.micinf. 2004.11.020

Lindgren, H., Stenmark, S., Chen, W., Tärnvik, A., and Sjöstedt, A. (2004). Distinct roles of reactive nitrogen and oxygen species to control infection with the facultative intracellular bacterium Francisella tularensis. Infect. Immun. 72, 7172-7182. doi: 10.1128/IAI.72.12.7172-7182.2004

Ma, Z., Russo, V. C., Rabadi, S. M., Jen, Y., Catlett, S. V., Bakshi, C. S., et al. (2016). Elucidation of a mechanism of oxidative stress regulation in Francisella tularensis live vaccine strain. Mol. Microbiol. 101, 856-878. doi: $10.1111 / \mathrm{mmi} .13426$

Maddocks, S. E., and Oyston, P. C. (2008). Structure and function of the LysR-type transcriptional regulator (LTTR) family proteins. Microbiology 154, 3609-3623. doi: 10.1099/mic.0.2008/022772-0

Man, S. M., Karki, R., Sasai, M., Place, D. E., Kesavardhana, S., Temirov, J., et al. (2016). IRGB10 liberates bacterial ligands for sensing by the AIM2 and Caspase-11-NLRP3 inflammasomes. Cell 167, 382-396.e17. doi: 10.1016/j.cell.2016.09.012

Melillo, A. A., Bakshi, C. S., and Melendez, J. A. (2010). Francisella tularensis antioxidants harness reactive oxygen species to restrict macrophage signaling and cytokine production. J. Biol. Chem. 285, 27553-27560. doi: 10.1074/jbc.M110.144394

Melillo, A. A., Mahawar, M., Sellati, T. J., Malik, M., Metzger, D. W., Melendez, J. A., et al. (2009). Identification of Francisella tularensis live vaccine strain $\mathrm{CuZn}$ superoxide dismutase as critical for resistance to extracellularly generated reactive oxygen species. J. Bacteriol. 191, 6447-6456. doi: 10.1128/JB. 00534-09

Meunier, E., Wallet, P., Dreier, R. F., Costanzo, S., Anton, L., Rühl, S., et al. (2015). Guanylate-binding proteins promote activation of the AIM2 inflammasome during infection with Francisella novicida. Nat. Immunol. 16, 476-484 doi: 10.1038/ni.3119

Michán, C., Manchado, M., Dorado, G., and Pueyo, C. (1999). In vivo transcription of the Escherichia coli oxyR regulon as a function of growth phase and in response to oxidative stress. J. Bacteriol. 181, 2759-2764.

Morgan, R. W., Christman, M. F., Jacobson, F. S., Storz, G., and Ames, B. N. (1986) Hydrogen peroxide-inducible proteins in Salmonella typhimurium overlap with heat shock and other stress proteins. Proc. Natl. Acad. Sci. U.S.A. 83, 8059-8063. doi: 10.1073/pnas.83.21.8059

Murphy, M. P., Packer, M. A., Scarlett, J. L., and Martin, S. W. (1998). Peroxynitrite: a biologically significant oxidant. Gen. Pharmacol. 31, 179-186. doi: 10.1016/S0306-3623(97)00418-7

Oyston, P. C., Sjöstedt, A., and Titball, R. W. (2004). Tularaemia: bioterrorism defence renews interest in Francisella tularensis. Nat. Rev. Microbiol. 2, 967-978. doi: 10.1038/nrmicro1045 
Polsinelli, T., Meltzer, M. S., and Fortier, A. H. (1994). Nitric oxide-independent killing of Francisella tularensis by IFN-gammastimulated murine alveolar macrophages. J. Immunol. 153, 1238-1245.

Pomposiello, P. J., and Demple, B. (2001). Redox-operated genetic switches: the SoxR and OxyR transcription factors. Trends Biotechnol. 19, 109-114. doi: 10.1016/S0167-7799(00)01542-0

Rhee, S. G., Chae, H. Z., and Kim, K. (2005). Peroxiredoxins: a historical overview and speculative preview of novel mechanisms and emerging concepts in cell signaling. Free Radic. Biol. Med. 38, 1543-1552. doi: 10.1016/j.freeradbiomed. 2005.02.026

Schaible, U. E., and Kaufmann, S. H. (2004). Iron and microbial infection. Nat. Rev. Microbiol. 2, 946-953. doi: 10.1038/nrmicro1046

Sjöstedt, A. (2006). Intracellular survival mechanisms of Francisella tularensis, a stealth pathogen. Microbes Infect. 8, 561-567. doi: 10.1016/j.micinf.2005. 08.001

Storz, G., Jacobson, F. S., Tartaglia, L. A., Morgan, R. W., Silveira, L. A., and Ames, B. N. (1989). An alkyl hydroperoxide reductase induced by oxidative stress in Salmonella typhimurium and Escherichia coli: genetic characterization and cloning of ahp. J. Bacteriol. 171, 2049-2055. doi: 10.1128/jb.171.4.2049-2055.1989

Troxell, B., and Hassan, H. M. (2013). Transcriptional regulation by Ferric Uptake Regulator (Fur) in pathogenic bacteria. Front. Cell. Infect. Microbiol. 3:59. doi: 10.3389/fcimb.2013.00059
Wei, Q., Minh, P. N., Dötsch, A., Hildebrand, F., Panmanee, W., Elfarash, A., et al. (2012). Global regulation of gene expression by OxyR in an important human opportunistic pathogen. Nucleic Acids Res. 40, 4320-4333. doi: 10.1093/nar/gks017

Whitby, P. W., Morton, D. J., Vanwagoner, T. M., Seale, T. W., Cole, B. K., Mussa, H. J., et al. (2012). Haemophilus influenzae OxyR: characterization of its regulation, regulon and role in fitness. PLoS ONE 7:e50588. doi: 10.1371/ journal.pone.0050588

Zheng, M., Aslund, F., and Storz, G. (1998). Activation of the OxyR transcription factor by reversible disulfide bond formation. Science 279, 1718-1721. doi: $10.1126 /$ science.279.5357.1718

Zheng, M., Doan, B., Schneider, T. D., and Storz, G. (1999). OxyR and SoxRS regulation of fur. J. Bacteriol. 181, 4639-4643.

Conflict of Interest Statement: The authors declare that the research was conducted in the absence of any commercial or financial relationships that could be construed as a potential conflict of interest.

Copyright (c) 2017 Honn, Lindgren, Bharath and Sjöstedt. This is an open-access article distributed under the terms of the Creative Commons Attribution License (CC $B Y)$. The use, distribution or reproduction in other forums is permitted, provided the original author(s) or licensor are credited and that the original publication in this journal is cited, in accordance with accepted academic practice. No use, distribution or reproduction is permitted which does not comply with these terms. 